\title{
A MEDIAÇÃO CULTURAL NO BACHARELADO EM BIBLIOTECONOMIA: UMA ANÁLISE DAS MATRIZES CURRICULARES DOS CURSOS NO BRASIL
}

\author{
THE CULTURAL MEDIATION IN THE BACHELOR'S DEGREE IN \\ LIBRARIANSHIP: AN ANALYSIS OF THE CURRICULAR MATRICES OF THE \\ COURSES IN BRAZIL
}

\author{
Bárbara Damiane da Silva , Luciane de Fátima Beckman Cavalcante ${ }^{I I}$
}

\begin{abstract}
Recebido em: 30-03-2019
Aceito em: 16-04-2019

\section{Resumo}

Este artigo apresenta como tema principal a mediação cultural, assunto pouco discutido na literatura da Ciência da Informação e desconhecido para muitos bibliotecários. Discute a mediação cultural e como ela é abordada nos cursos de formação de bibliotecários. Nesse sentido, como objetivo geral pretendeu analisar a inserção da temática da mediação cultural nos currículos de graduação dos cursos de Biblioteconomia no Brasil. Os objetivos específicos centraram-se em verificar nas matrizes curriculares dos cursos de biblioteconomia a inserção da temática da mediação cultural e examinar as bibliografias dos cursos para verificar se o referencial teórico utilizado aborda a mediação cultural, além de averiguar, por meio dos programas de disciplinas, se os docentes abordam temas relacionados à cultura em suas disciplinas. O universo da pesquisa concentrou-se nas matrizes curriculares dos cursos de Biblioteconomia no Brasil e nos planos de ensino. Foi realizada uma pesquisa de natureza qualitativa exploratória, em que se optou por realizar uma pesquisa documental. Sendo assim, foram analisadas as matrizes curriculares dos cursos e os planos de ensino de determinadas disciplinas, as quais foram identificadas mediante a utilização de determinados termos como filtros (mediação, cultura, mediação cultural e mediação da informação). A partir da análise dos dados foi constatado que não existe uma grande atenção voltada para a abordagem da cultura nas matrizes curriculares dos cursos de Biblioteconomia no Brasil e obteve-se o resultado de que apenas $13 \%$ das universidades apresentam no plano de ensino e no conteúdo programático da disciplina a abordagem referente à mediação cultural. Desta forma, apontamos a necessidade de uma reforma nas matrizes curriculares de algumas instituições e a imprescindível inclusão da mediação cultural na formação do bacharel em Biblioteconomia.
\end{abstract}

Palavras-chave: Mediação cultural. Cultura. Mediação. Histórico da Biblioteconomia. Matrizes curriculares-Biblioteconomia.

\begin{abstract}
This article presents as main theme the cultural mediation, a subject little discussed in the Information Science's literature, unknown for many professionals. It discusses cultural mediation and how it is approached in the training courses for librarians. The aim of the research was to analyze the insertion of the theme of cultural mediation in the undergraduate curriculum of the courses of Librarianship in Brazil with the specific objective to verify in the curricular matrices of the courses of librarianship the insertion of the theme of cultural mediation and to examine the bibliographies of the courses to verify if the theoretical reference used approaches cultural mediation, to ascertain, through the programs of disciplines if the teachers approach subjects related to the culture in their disciplines. The research universe focuses on the curricular matrices of the Librarianship courses in Brazil and on the teaching plans. This research has a qualitative exploratory nature, where it was decided to carry out a documentary research, when the curricular matrices of the courses and the teaching plans of certain disciplines were analyzed, which were identified through the use of certain terms as filters (mediation, culture, cultural mediation and mediation of information). The documents were collected on the official
\end{abstract}

\footnotetext{
${ }^{\text {I }}$ Mestre em Ciência da Informação - UFPR - e-mail: babidamiane@gmail.com

II Universidade Federal do Paraná - e-mail: lucifbc@gmail.com
} 
websites of the institutions that offer the courses in Brazil, in cases where this information was not available the contact was made by e-mail and by telephone with the course departments, however in some cases even after several contacts requesting the documents, we did not receive a response. Analyzing the data, we also noticed that there is a great deal of attention focused on the culture approach in the curricular matrices of the Librarianship courses in Brazil and we have obtained the results that only 13\% of the universities present in the plan of teaching and the syllabus content of the discipline to approach cultural mediation. Therefore, we point out the necessity out of a reform in the curricular matrices of some institutions and thus indispensable for the inclusion of cultural mediation in the formation of the bachelor in Library Science.

Keywords: Cultural mediation. Culture. Mediation. History of Librarianship. Curricular matricesLibrarianship.

\section{INTRODUÇÃO}

Nos estudos relacionados à Ciência da Informação (CI), muito se fala em mediação da informação, assim, de certa forma, as outras variáveis, tais como a mediação cultural, pedagógica, da leitura, da leitura literária, da leitura oral, dentre outras, são negligenciadas. Desse modo, com o intuito de contribuir com o escopo bibliográfico da CI, o tema desta pesquisa refere-se à mediação cultural.

O referencial teórico, então, centra-se na temática da Mediação Cultural, sendo indispensável discutirmos e conceituarmos a mediação da informação, bem como o termo mediação e cultura. Essas conceituações contribuíram para contextualizar e introduzir os conceitos básicos e fundamentais a fim de compreender a mediação da informação e a mediação cultural juntamente com as práticas culturais.

Além da definição dos principais conceitos que embasam teoricamente esta pesquisa, também foram abordados o surgimento das escolas de Biblioteconomia no Brasil, a criação e estruturação dos cursos, a lei que regulamenta a profissão de bibliotecário, os direitos e deveres dos profissionais e o perfil desejado para a atuação na área. Essa discussão é o ponto de partida para debater e analisar a formação do bacharel em Biblioteconomia e, por fim, responder à questão problema desta pesquisa. Para isso, o universo de pesquisa centrou-se nas matrizes curriculares dos cursos de Biblioteconomia no Brasil.

Para atender e responder a todos os objetivos propostos nesta pesquisa, optamos por utilizar nos procedimentos metodológicos uma abordagem qualitativa, de caráter exploratório, sendo que a coleta dos dados foi realizada a partir do levantamento das matrizes curriculares, dos programas das disciplinas que abarcam o tema pesquisado.

A análise dos dados coletados passou por três fases e as informações foram separadas por categorias. A primeira fase teve como objetivo verificar a presença de disciplinas que ministram o tema mediação cultural e seus correlatos. Na segunda fase, o intuito foi analisar o conteúdo programático da disciplina, no qual a proposta foi verificar através da bibliografia sugerida pelo professor, a utilização de textos que abordem a mediação cultural.

Assim sendo, ao investigarmos as matrizes curriculares dos cursos, houve a possibilidade de comprovar ou não uma hipótese levantada anteriormente, em pesquisa realizada para o Trabalho de Conclusão do Curso (TCC) em Biblioteconomia, com o título a "Mediação cultural e suas práticas: Um estudo no Sistema de Bibliotecas Públicas Municipais de Londrina".

A pesquisa consistiu em investigar se os bibliotecários sabiam conceituar a mediação cultural e suas práticas. Para isso, aplicamos um questionário e constatamos que a maioria dos bibliotecários não sabia conceituar a mediação cultural e nem diferenciar as práticas culturais. A partir dos dados, hipotetizamos que essa confusão ou ausência de informação sobre este tipo de mediação e suas práticas ocorria pela possível falta de capacitação no curso de 
Biblioteconomia. Desta forma, na atual pesquisa por meio dos dados levantados foi possível confirmar esta hipótese levantada.

Acreditamos que o cenário de poucas publicações e discussões resulta na falta de capacitação dos futuros bibliotecários e na confusão sobre a conceituação de mediação cultural e consequentemente em relação às práticas que podem ser realizadas. Assim, os profissionais enfrentam dificuldades ao não encontrarem materiais para se embasarem teoricamente e buscarem a informação necessária para o desenvolvimento das atividades.

Em um relato de experiência pessoal na carreira profissional da proponente desta pesquisa, onde a mesma faz parte de um grupo de bibliotecários, os quais ao serem incumbidos de desenvolver um projeto que tinha como objetivo de ampliar o uso da biblioteca demonstraram um apreço à cultura e assim propuseram como prática biblioteconômica, o uso da mediação cultural para o desenvolvimento da tarefa. Após delimitar o tipo de mediação, os profissionais tiveram como barreiras o pouco conhecimento sobre o assunto e também o número escasso de publicações acerca do tema na área.

Desta maneira, observamos que os empecilhos encontrados pelos bacharéis em Biblioteconomia relacionam-se com a hipótese levantada no Trabalho de Conclusão de Curso, no ano de 2016, ou seja, assinalamos a necessidade de ampliar a discussão sobre mediação cultural na área da Biblioteconomia.

A observação da demanda na área da Biblioteconomia por um profissional capacitado para o desenvolvimento de atividades com o uso da mediação cultural manifestou-se, também, por meio de um edital de concurso público da prefeitura de Londrina, no Paraná. No citado edital de concurso $n^{\circ}$ 172/2015, consta no Anexo I, referente às atribuições dos cargos, a vaga de gestor cultural. O edital solicitava, entre os requisitos para o cargo, curso superior em Biblioteconomia e registro no Conselho Regional de Biblioteconomia (CRB), e entre as atribuições estava a de "planejar, implementar e executar atividade de extensão cultural" (LONDRINA, 2015).

Sobre a formação do profissional bibliotecário, as Diretrizes Curriculares Nacionais de 2001 já apontavam que os cursos de Biblioteconomia, além de propiciarem aos estudantes o desenvolvimento de competências, habilidades e o domínio dos conteúdos da Biblioteconomia, devem capacitá-los para resolver com criatividade e domínio os problemas encontrados na prática biblioteconômica. O referido documento, ainda, recomenda que, para os cursos atenderem ao que é proposto dentro da diretriz, os conteúdos programáticos e os projetos acadêmicos devem acentuar na formulação dos conteúdos a "adoção de uma perspectiva humanística, conferindo-lhes um sentido social e cultural que ultrapasse os aspectos utilitários mais imediatos", sugerindo que podem ser adotadas modalidades de parceria com outros cursos. (BRASIL, 2001).

Ressaltamos a importância de abordar a mediação cultural, tendo como referência Cabral (1999), pois a autora aponta que o uso das práticas culturais relacionadas à mediação cultural foi imprescindível para as bibliotecas porque contribuiu para o estímulo da leitura e uso destes espaços. Sendo assim, acreditamos que a utilização deste tipo de mediação contribuiria para a visibilidade e ampliação do uso das unidades informacionais.

As experiências vividas no âmbito acadêmico do curso e no mercado de trabalho nos levam a questionar se, realmente, as disciplinas ministradas no curso de graduação são suficientes, abordam as possíveis linhas de atuação do bibliotecário e seguem as informações presentes na Diretriz Curricular Nacional do curso de Biblioteconomia.

Assim sendo, esta pesquisa teve o intuito de comprovarmos se a formação do bibliotecário propicia ao profissional graduado desenvolver atividades relacionadas à mediação cultural. A partir disso, a pesquisa também pretende promover discussões em torno da formação do profissional. Para isto, esta pesquisa teve como objetivo geral analisar a inserção da temática da mediação cultural nos currículos de graduação do curso de Biblioteconomia no Brasil e os 
objetivos especificos de verificar nas matrizes curriculares dos cursos de biblioteconomia a inserção da temática da mediação cultural; averiguar, por meio dos programas de disciplinas se os docentes abordam temas relacionados à cultura em suas disciplinas; examinar as bibliografias dos cursos para verificar se o referencial teórico utilizado aborda a mediação cultural.

\section{MEDIAÇÃO E A MEDIAÇÃO DA INFORMAÇÃO}

$\mathrm{O}$ assunto central desta pesquisa é a mediação cultural, portanto, torna-se relevante contextualizar a mediação da informação. Desta forma, iremos apresentar os conceitos de mediação e mediação da informação presentes na literatura da Ciência da Informação, além de conceituar mediação implícita e explícita. Para isso, os conceitos dos autores como Signates (1998), Almeida Junior (2009) e Davalon (2007) desenvolveram sobre o assunto orientam a discussão.

Signates (1998) atenta para o fato de que, em 1998, havia um número elevado de citações e usos dos termos mediação e mediador, além do verbo mediar. Na opinião do autor, esta variedade de citações deveria resultar em um consenso e clareza na conceituação dos termos.

Entretanto, observamos que persiste a confusão a respeito do conceito de mediação. Consideramos que essa falta de consenso está relacionada às diferentes vertentes e influências que contribuem para formar a concepção de mediação. Para fundamentar esta hipótese serão apresentados fatos históricos e as linhas de estudo ligadas ao assunto.

A definição do termo estaria ligada ao adjetivo, em inglês, mediate, mas também possui ligação com o termo francês mediat, que depois originou o substantivo médiation e intermediation, como um de seus derivados. A mediação origina-se de duas linhas filosóficas: a idealista e a hegeliana (SIGNATES, 1998).

Segundo Signates (1998), a vertente idealista tem origem cristã e estaria conectada à herança teológica, que, em seguida, se sustenta nas bases do existencialismo. A partir de então, o termo passa a carregar o significado de conciliação entre dois opostos. Na vertente hegeliana, com herança do marxismo, a mediação relaciona-se à transformação das produções das mudanças no espaço de cultura. É nesta vertente que se apresenta a ideia do objeto que antecede a mediação, que seria a noção de reflexo.

Para Davallon (2007), ao analisar a produção científica na Ciência da Informação e da Comunicação, o uso do termo mediação possui o sentido de fazer intermédio entre partes, de colocar em acordo universos em discordância, em que se pressupõe criar formas de conciliação ou reconciliação entre eles, assim, estaria relacionado ao uso do senso comum para a sua definição de mediação.

O referenciado autor apresenta, ainda, dois usos para o termo:

- $\quad$ O uso operatório: de utilizar a palavra para descrever ou analisar um processo específico, fazendo uso de um ator social. Seria, neste caso, a mediação de uma técnica utilizada, e é dentro deste uso que se contextualiza a mediação mediática, mediação pedagógica, mediação cultural, dentre outras. Assim sendo, é na perspectiva deste uso do termo que esta pesquisa se aplica.

O uso para uma definição teórica: o de produzir e conduzir uma definição teórica, com uma abordagem suficientemente clara e precisa para a definição do vocábulo.

Por outro lado, Darras (2009) conceitua mediação a partir do ponto de vista Pierciano da estrutura do signo. Assim, para o autor, a mediação seria:

[...] um processo de acompanhamento semiótico e de inter-relação semiótica necessário que intervém em cada ocasião de fabricação dos signos. [...] $\mathrm{O}$ mediador (dispositivo, máquina ou humano), com um intérprete, insinua-se 
no processo semiótico elementar para Ihe inserir os interpretantes destinados a facilitar, desenvolver, efetivar, enriquecer, ampliar e mesmo questionar o processo interpretativo (DARRAS 2009, p. 36).

Desta forma, para o supracitado autor, a mediação seria uma ação que tem como finalidade levar significação e significado de algo ou alguma coisa. Para isso, o mediador (intérprete) realiza processos fazendo uso de objetos, tais como a informação e a cultura, a fim dos mesmos criarem e darem significação e significado para o mediado (interpretantes).

Para iniciarmos o discurso sobre os tipos de mediações existentes, apresentamos algumas que foram levantadas por Santos Neto (2014), que por meio de sua participação em leituras, discussões e pesquisas referentes ao assunto dentro do grupo de pesquisa "Interfaces: informação e conhecimento", realizou o seguinte levantamento das mediações existentes: Mediação eletrônica, mediação escolar, mediação histórica, mediação custodial, mediação da ritualidade, mediação da leitura literária, mediação cultural, mediação de leitura, mediação da sensibilidade e dentre outras mediações.

Por meio do levantamento do referenciado autor, verificamos que existem várias formas e tipos de mediação, as quais apresentam conceitos e contextos diferentes, variando conforme a vertente que está sendo abordada. Chegamos à conclusão que conceituar e contextualizar todas estas formas seria demasiadamente extenso e exaustivo para esta pesquisa. Observamos também que é impossível falar de mediação sem citar a mediação da informação, tão presente e discutida na Ciência da Informação.

Assim sendo, iniciamos a discussão a respeito da mediação da informação apresentando a conceituação defendida por Almeida Júnior. Para o autor mediação da Informação é:

[...] toda ação de interferência - realizada pelo profissional da informação -, direta ou indireta; consciente ou inconsciente; singular ou plural; individual ou coletiva; que propicia a apropriação de informação que satisfaça, plena ou parcialmente, uma necessidade informacional (ALMEIDA JÚNIOR, 2009, p. 92).

Dessa maneira, utilizaremos o conceito de Almeida Junior (2009), no qual observamos que a interferência está relacionada ao ato de mediar em si, quando o profissional da informação se utiliza do seu conhecimento para construir e desenvolver a mediação. Neste ponto, o autor observa que o profissional bibliotecário é aquele responsável em mediar a necessidade informacional do usuário, que seria então a informação suficiente para satisfazê-lo. De uma forma geral, notamos que a mediação está envolta em todo o processo que a informação perpassa, desde o seu tratamento e armazenamento até a sua disseminação e apropriação.

O autor afirma que a mediação pode ser direta ou indireta. Almeida Júnior (2009) também discorre sobre os conceitos de mediação explícita e implícita em sua perspectiva:

- $\quad$ Explícita - Neste caso, para que a mediação ocorra é imprescindível a presença do usuário, pois sem o mesmo ela não ocorreria. Está relacionada às atividades fins, sendo que, nesta fase, a fonte de informação já está disponível para o acesso do usuário. Ainda para Almeida Junior (2009), nesse processo, pode ocorrer a mediação explícita/explícita e a explícita/implícita. A primeira corresponderia às ações desenvolvidas de forma consciente, por meio do conhecimento dominado e exteriorizado de forma controlada. A segunda, seriam ações em que o conhecimento inconsciente sobrepõe-se ao conhecimento consciente.

- Implícita- A mediação ocorre na ausência do usuário, estaria mais relacionada às atividades da seleção, armazenamento e processamento da informação, como a indexação e a catalogação.

O supracitado autor, também afirma que certos conceitos possuem uma abrangência de discussões e outros temas circulam em determinados eixos acadêmicos, o que dificultaria o 
aprofundamento das reflexões sobre estes mesmos conceitos. Na opinião de Almeida Junior (2015), este seria o caso dos conceitos de mediação da informação e da mediação cultural no âmbito da Ciência da Informação. Por este motivo daremos continuidade às discussões sobre estas duas áreas da CI, apresentando, no próximo capítulo, os conceitos de mediação cultural, tendo como ponto de partida a conceituação de cultura.

\section{CULTURA E A MEDIAÇÃO CULTURAL}

Neste ponto, serão apresentados e discutidos os conceitos de cultura e mediação cultural. A conceituação de cultura torna-se importante devido à complexidade dos conceitos existentes e também para compreender como a mediação ocorre no contexto cultural. Os estudos de Brito (2016) fazem referência às discussões de Dufrêne e Gellereau (2004) na qual as autoras apontam que a mediação possui dois níveis dentro da cultura. O nível de manifestação, que está relacionada às atividades dos profissionais para o público e com o público, e o nível das políticas de desenvolvimento de atividades culturais.

Dessa forma, é preciso, inicialmente, entender que o termo cultura vem do latim colere, que significa cultivar, relacionando-se a tudo aquilo que o indivíduo adquire, nã o só por meio da família, mas também a partir da sociedade da qual ele faz parte. Portanto, ele necessita disso para melhor viver em sociedade, local onde a cultura é propagada para gerações futuras. Outra questão a destacar é que podem ocorrer algumas mudanças para que a mesma se adapte à atual sociedade (CANEDO, 2009).

O conceito de cultura apresentado por Canedo (2009) mostra que os estudos iniciais a respeito do termo cultura surgem nos séculos XVIII e XIX, especialmente desenvolvidos pelos alemães e franceses. Na época, o termo era empregado com o objetivo de explicar um assunto e seguido de um complemento como, por exemplo, culturas das letras, culturas das artes, etc.

Os franceses seguiam a vertente iluminista e universalista, em que a cultura estava relacionada ao estado de espírito, mas também à educação, à evolução e à razão. Para os alemães, a significação de cultura apresentava similaridade com o conceito francês, entretanto, compreendiam a cultura como civilização, sendo esse o sentido utilizado pelos príncipes da aristocracia alemã (CANEDO, 2009).

Segundo Santos (2006), a cultura, de modo simplista, é tudo aquilo que faz referência à nossa sociedade, além de existir, obviamente, as especificações que correspondem a um grupo de pessoas, uma nação, uma classe social, dentre outros. Essas especificações ou variações de culturas, apresentadas pelo autor, geram muitas discussões na atualidade, questiona-se quais são essas variações e o porquê delas ocorrem.

Para Canedo (2009), cultura apresenta um caráter transversal, pois percorre diferentes áreas e sentidos da vida cotidiana e ainda é utilizada em áreas multidisciplinares do conhecimento, o que aumenta o número de possibilidades para a compreensão dela.

Os estudos sobre cultura nos mostram que existem várias distinções dependendo de quais aspectos são abordados. Desta forma, estas abordagens criam concepções diferentes e, assim, Santos (2006) apresenta duas concepções de cultura:

$1^{\circ}$ - Reporta-se a todas as expressões: em que se preocupa com todas as expressões sociais, é tudo aquilo que caracteriza uma realidade social de um povo específico ou de uma nação como um todo. Esta concepção é utilizada de modo genérico, é mais usual quando se discute sobre povos e nações muitos distintos entre si;

$2^{\circ}$ - Remete-se para o conhecimento: em que está relacionada às ideias e crenças e à forma como elas existem na vida social. Nesta concepção, também são abordadas as culturas alternativas, as quais compreendem as tendências dos modos de se viver em sociedade, onde as realizações individuais são enfatizadas. 
Observamos acima que as concepções apresentadas por Santos (2006) estão relacionadas às expressões e ao conhecimento de uma sociedade. Porém, devido à multiplicidade de interpretações de cultura, Canedo (2009) apresenta três concepções que são:

$1^{\circ}$ - Modos de vida que caracterizam uma coletividade: está relacionada a um sistema de signos e significados criados pelos diversos e distintos grupos sociais, em que a cultura é produzida por meio da interação social. Valoriza o patrimônio imaterial da cultura, como as tradições orais, os costumes, as crenças, a organização social de cada comunidade como um todo;

$2^{\circ}$ - Obras e práticas da arte, da atividade intelectual e do entretenimento: é classificada pelo autor como uma visão mais restrita da cultura, pois refere-se e visa as atividades econômicas, tais como as obras de arte e de entretenimento. Desta forma, sua produção é elaborada e possui um objetivo explícito de se construir determinados sentidos e de alcançar um público e assim não ocorre no cotidiano, mas de forma especializada. A produção e distribuição desta cultura produzida foi fundamental para o desenvolvimento dos países, uma vez que o consumo de bens e serviços movimentaram a comercialização e consequentemente contribuíram para o desenvolvimento econômico. Nesta concepção, a cultura passa por dois processos distintos - o de mercantilização, em que as atividades culturais são produzidas visando o lucro e a distribuição em massa, e a de culturalização da mercadoria, que ocorre por meio da atribuição de valores simbólicos aos objetos do cotidiano;

$3^{\circ}$ - Fator de desenvolvimento humano: estaria relacionada ao papel de desenvolvimento social, em que as atividades têm o desígnio socioeducativo para estimular o senso crítico, desenvolvimento cognitivo em pessoas com deficiência e ainda atividades terapêuticas. É também utilizada para objetivos educacionais a fim de incentivar o interesse dos alunos e o auxílio para a resolução dos problemas sociais, tais como a violência e reinserção de presos ou jovens infratores na sociedade, dentre outros.

Podemos inferir que ao utilizar a cultura para fins educacionais, além de auxiliar na formação escolar, por meio dos estudos de outras culturas, a reconhecemos como um fator de mudança social. Também compreendemos que a cultura não está apenas ligada às manifestações artísticas ou às festas regionais ou tradicionais, ou ainda à cultura de massa como a conhecemos, mas possui o seu fator de desenvolvimento social.

Para além das diferentes concepções de cultura, existem também as variações culturais (gírias, costumes religiosos, dentre outros), através das quais ocorreram algumas tentativas de ordenar as variações, colocando-as em um único sistema rígido de um esquema de etapas. Foram os chineses e os europeus que tentaram, de alguma forma, ordenar essas variações, mas, mesmo com essa intenção de ordenação, não é possível elencar as sequências ou fases culturais pelas quais cada uma delas passou, esta atividade foi vista de forma negativa por Santos (2006).

Por fim, seguindo as observações de Santos (2006), inferimos que cada cultura possui a sua realidade lógica interna. $\mathrm{O}$ autor considera que os sujeitos deveriam conhecer culturas diferentes das que estão acostumados, para que, assim, possam compreender as suas práticas, costumes, concepções e as transformações. Seria uma maneira de desconstruir o preconceito que existe em relação às culturas desconhecidas, muitas vezes, pelo indivíduo. Segundo o autor, para compreender sobre cultura tem-se que pensar nos diversos tipos de povos, grupos sociais e de pessoas, pois existe uma interação entre todos esses grupos.

Para iniciarmos as discussões sobre a mediação cultural, retomamos os debates a respeito da cultura. Essas discussões surgiram na França, na década de 1970, quando são criados os Ministérios dos Assuntos Culturais e as Casas ou Centros de Cultura (Maisons de la Culture), tendo à frente André Malraux. A criação das políticas culturais francesas apoiadas e patrocinadas pela Organização das Nações Unidas para Educação, Ciência e Cultura (UNESCO) possibilitaram a emergência do assunto em caráter mundial (RASTELI; CALDAS, 2015). 
Para Quintela (2011), é neste momento que as questões culturais assumem relevância política e programática, abrindo o tema para discussões que destacam a importância do desenvolvimento de programas de formação e qualificação e a atração de público para as artes e para a cultura. E assim, a cultura assume um espaço estratégico da hegemonia e passa a mediar, nos dispositivos de mediação de massa ela "encobre o conflito entre as classes produzindo sua resolução no imaginário" (MARTÍN-BARBERO, 2009 P.175).

No Brasil, segundo Rasteli e Caldas (2015), as discussões sobre as práticas relacionadas à cultura acentuaram-se em 1980. Este debate tem como referência o conceito de práticas culturais cunhado por Francis Jeanson, em 1973. O autor defende que os processos de práticas culturais são fundamentais para a criação ou organização de condições necessárias para que as pessoas criem seus próprios fins e, assim, tornem-se sujeitos da cultura.

Ainda de acordo com Rasteli e Caldas (2015), no Brasil, os termos mediação e mediador cultural vieram contrapor-se aos de ação e agente cultural. Isso devido ao fato de que a ação cultural era vista como sendo uma atividade profissional de interação entre moral e conhecimento e a mediação cultural como um processo dialógico.

Sendo assim, o termo mediação cultural passou a ser evidenciado, na América Latina, a partir da produção de Martin-Barbero, em seu livro "Dos meios às mediações: comunicação, cultura e hegemonia", de 1987, em que o autor apresenta os estudos referentes à cultura e à ideia de mediação como lugar de significação. O citado trabalho de Martin-Barbero recebe algumas críticas de outros autores devido ao fato de que o autor não propõe, em sua obra, uma definição conceitual do que seria a mediação cultural.

Mesmo com essa lacuna referente ao conceito da mediação, segundo Oliveira (2014), Martin-Barbero é um autor referencial no campo dos estudos sobre cultura e aborda as mediações como lugares de interações entre receptor e produtor, a fim de propiciar a produção e reprodução de significados sociais.

Em seu livro "Dicionário crítico de política e ação cultural", Teixeira Coelho apresenta várias definições e verbetes para inúmeros assuntos, além de apresentar os termos que os relacionam. E, desta forma, mediação cultural para Teixeira Coelho (1999) é:

Processos de diferente natureza cuja á meta é promover a apropriação entre indivíduos ou coletividades e obras de cultura e arte. Essa aproximação é feita com o objetivo de facilitar a compreensão da obra, seu conhecimento sensível e intelectual - com o que se desenvolvem apreciadores ou espectadores, na busca da formação de públicos para a cultura - ou de iniciar esses indivíduos e coletividades na prática de uma determinada atividade cultural (TEIXEIRA COELHO, 1999, p. 247).

A partir da definição do referido autor, podemos destacar algumas questões relevantes e que se relacionam com a construção do processo de mediação cultural:

Processos de diferente natureza: estes processos apresentados por ele seriam as práticas culturais existentes, tais como a ação cultural, animação cultural, fabricação cultural, confinamento cultural, dentre outras atividades. São de diferentes naturezas, pois cada uma possui uma característica, um objetivo e uma forma de serem apresentadas ao público. Estas características de cada prática cultural serão apresentadas posteriormente;

- Conhecimento sensível e intelectual: a aproximação com a obra permite a compreensão do indivíduo para com a arte, possibilitando então uma leitura e releitura do objeto artístico, criando, assim, a sensibilidade para o objeto e, sem dúvida, possibilitando agregar valor para o conhecimento intelectual, uma vez que o espectador passa a compreender um novo campo ou uma nova área. 
- Desenvolver apreciadores ou espectadores: este fator está relacionado à aproximação do indivíduo ao objeto cultural e a uma possível apropriação cultural, visando o despertar para as obras de arte.

- $\quad$ Busca de formação de públicos: a formação de público pode ser relacionada apenas à apreciação cultural ou quando aplicada dentro das unidades informacionais é utilizada para a formação de público para a biblioteca.

Complementando as definições de Teixeira Coelho (1999), Davallon (2007) conceitua a mediação cultural como sendo uma atividade que visa o despertar do público para as obras, com ações que consistem em criar uma interface entre esses dois universos distintos. Dessa maneira, concorda com as definições de mediação de Teixeira Coelho, ou seja, a ideia de colocar em comum acordo universos distintos ou em atrito.

Por meio dos autores referenciados, podemos inferir que a mediação cultural é um nível ou fator de regulação, de intermédio entre estas partes em conflito. Esta modalidade de mediação, assume, por isso, o nível de regulação, pois o conflito existente entre as partes não ocorre de forma direta, o que ocorre é a falta de interação entre os indivíduos e a cultura.

Enquanto que para Davallon (2007) o processo de mediação pode ocorrer de forma precisa, para Perrotti e Pieruccini (2014), a mediação cultural ocorre por meio de processos difusos. De acordo com Perrotti e Pieruccini (2014), é preciso considerar os diversos espaços e equipamentos culturais e ainda a diversidade das manifestações que ocorrem nestes equipamentos. Os autores citam como exemplo a ação de mediação na gestão ou constituição de acervos.

Os processos de mediação podem seguir três aspectos pertinentes à CI. O primeiro está relacionado à concepção de mediação como produto/resultante da ação dos meios de comunicação e informação. O segundo é o papel dos mediadores frente às possibilidades abertas ou fechadas pelas novas tecnologias da informação e da comunicação e o terceiro, a formação de profissionais da Ciência da Informação aptos a responderem aos dois pontos anteriores (ALMEIDA, 2007).

Os processos para que ocorra a mediação cultural podem ser complexos e, como aponta Darras (2009), é preciso o encontro entre quatro fatores: o objeto cultural utilizado; as representações, crenças e conhecimento do mediado; as representações, crenças, conhecimento e competências do mediador; mundo cultural de referência. Sendo assim, quando esses fatores encontram-se é que ocorre a mediação pela cultura. Neste ponto, o autor reforça que alguns critérios como as referências culturais e as posições sociais dos envolvidos podem diferenciar a mediação cultural.

Para findarmos, inferimos que, para além das controvérsias a respeito dos conceitos e definições, os estudos sobre este tipo de mediação esbarram nos conceitos de cultura, que são diversos e cada um pode adotá-los de uma forma. Sendo assim, consideramos que este tipo de mediação sofre influência da concepção de cultura que o mediado e o mediador possuem, aliado às referências de cultura e, por fim, às suas posições sociais e culturais.

Por acreditarmos que a realidade no Brasil é diferente de outros países e analisando o problema e as justificativas que fomentam esta pesquisa, indagamos sobre o contexto brasileiro para a formação do bibliotecário referente à mediação cultural. Desta forma, no próximo capítulo, apresentamos o histórico da formação do bibliotecário no Brasil, como surgiu a necessidade da capacitação deste profissional e quais os caminhos trilhados pelo curso de Biblioteconomia até chegar à regulamentação da profissão. 


\section{HISTÓRICO DO ENSINO EM BIBLIOTECONOMIA NO BRASIL}

Apresentamos, aqui o histórico do ensino em Biblioteconomia no Brasil e das primeiras escolas de Biblioteconomia implantadas no país, além de mapear as atuais instituições de ensino que ofertam o curso para a formação do bacharel.

O primeiro curso de Biblioteconomia foi criado no Brasil em 1911, por meio do decreto 8.835. O curso tinha duração de dois anos, era ofertado pela Biblioteca Nacional, tendo como função a capacitação de pessoal para desempenhar as atividades na instituição. $O$ decreto que criou o curso de formação orientava sobre sua estrutura curricular.

Conforme o decreto, os ingressantes deveriam realizar prova escrita de português e oral de geografia, história universal e literária e, por fim, dos idiomas francês, inglês e latim. As aulas tinham caráter teórico e prático, com a duração de uma hora e uma vez por semana, se necessário havia a possibilidade de marcar mais aulas práticas.

Segundo Silveira (2007), mesmo o curso tendo uma grade de disciplinas fechada e desarticulada, seguia as bases do modelo francês da École des Chatres, que tinha como objetivo formar um profissional com perfil erudito e humanístico conservador e, por esse motivo, enfatizava as disciplinas voltadas aos aspectos culturais. $\mathrm{O}$ curso sofreu algumas interrupções e retornou em 1931 com reestruturações no currículo.

Além do curso ofertado pela Biblioteca Nacional, em 1929, o Colégio Mackenzie, na cidade São Paulo, inaugurou outro curso de formação de bibliotecários, que seguia as ideologias de Rubens Borba de Moraes e Adelpha Figueiredo, ambos formados por escolas norteamericanas, dentro do modelo Deweyano. Desta forma, as ênfases das disciplinas seguiam para as linhas de catalogação, classificação, referência e organização de documentos informacionais (SILVEIRA, 2007).

Segundo o supracitado autor, ao seguir o modelo Deweyano, o curso paulistano enfocava as técnicas de tratamento da informação aliadas ao uso dos sistemas de classificação existentes na época, tendo a pretensão de formar profissionais aptos a trabalhar com os instrumentos necessários para a circulação do conhecimento e da informação.

Sendo assim, diferentemente do curso ofertado pela Biblioteca Nacional, em que o objetivo era formar profissionais para uma demanda da instituição, o do Colégio Mackenzie pensava no usuário da biblioteca. Desta maneira, formava profissionais que poderiam proporcionar aos seus usuários terem as necessidades informacionais atendidas, por meio dos serviços ofertados pela biblioteca.

Já na década de 1940, o curso da Biblioteca Nacional passa por uma nova reforma, apoiado pelo governo federal e pela Fundação Rockefeller, a partir de então, oferecendo bolsas de estudos para ingressantes de outros estados. Com esta reforma, que ocorreu na administração de Rodolfo Augusto de Amorim Garcia, por meio do decreto 6.640, começou a formar bibliotecários para atuarem nos diversos tipos de biblioteca e não só para atender à necessidade da BN (CASTRO, 2000).

Ao analisarmos a reforma que o curso sofreu, podemos inferir que neste formato foram suprimidas algumas de suas características de formação humanística e voltou-se para a formação tecnicista, ainda que os cursos ofertados de forma avulsa fossem a primeira formação continuada ou uma primeira especialização voltada para a área. Este caráter tecnicista que o curso da $\mathrm{BN}$ adquiriu assemelha-se às características das escolas de formação norte-americanas, cuja linha de ensino vinha sendo aplicada em São Paulo. Depois que os cursos ofertados pela BN e em São Paulo passam por reformas, começam a receber alunos de outros estados do país e tornam-se um marco para a difusão da profissão no Brasil. A presença desses profissionais em outras regiões foi fundamental para a criação de novas escolas de formação de bibliotecários.

Como vimos anteriormente, as escolas que ofertavam o curso de Biblioteconomia no Brasil, situadas no Rio de Janeiro e em São Paulo, tinham como influência a linha tecnicista 
vinda da escola americana Columbia University e a influência humanística da escola francesa École de Chartes. Porém, com as reformas que ambas as escolas precisaram realizar em suas disciplinas ofertadas, a diferença entre as duas instituições diminuiu. Conforme aponta Castro (2000), posteriormente, ocorreram novas remodelações curriculares nos cursos de São Paulo e Rio de Janeiro, recebidas de forma negativa, uma vez que as mesmas não levaram em consideração as necessidades e as características regionais.

Mesmo com a aprovação da lei de 1962, em que garantia os direitos trabalhistas dos bibliotecários, os estudos em Biblioteconomia na época apontavam que no Brasil a área estava em crise, esse alerta também foi feito pela Comissão da Diretoria de Ensino Superior do Ministério da Educação. Os motivos desta crise eram apontados pela ausência de um currículo mínimo, uma suposta incapacidade dos bibliotecários em acompanharem tecnicamente a produção científica mundial, baixo reconhecimento social do papel do profissional e ensino eminentemente técnico (CASTRO, 2000).

Para tentar solucionar a crise da profissão, segundo Castro (2000), surgiram debates a respeito da falta de uniformidade para a formação do profissional. Para sanar este impasse, o diretor de ensino superior convocou uma comissão de especialistas em Biblioteconomia, tendo como base o artigo $1^{\circ}$ da lei 4.084/62 e o artigo 60 da lei de Diretrizes da Educação Nacional, para a elaboração de uma proposta de um currículo mínimo, que seria encaminhado para o Conselho Federal de Educação.

Mas, conforme Silveira (2007), esta intenção já havia sido discutida anteriormente, quando do debate em torno do denominado currículo básico, em que as disciplinas foram separadas entre as "profissionais" e as "não profissionais". A partir deste currículo, se acirraram as discussões entre a formação tecnicista e a humanista do bibliotecário.

No currículo básico, as disciplinas "profissionais" eram as seguintes: Bibliografia e referência; Catalogação e classificação especializada; Catalogação; Classificação; História dos livros e das bibliotecas; Organização e administração de bibliotecas; Técnicas de documentação. As "não profissionais", motivo de desacordo entre os diretores das escolas, pois alguns as consideravam irrelevantes para formação do profissional, estavam assim estruturadas: Ciência filosófica; História da literatura ou Bibliografia literária; Introdução à cultura histórica, literária, artística e científica; Seleção e orientação de leitores (SILVEIRA, 2007).

Ao analisarmos este conjunto de disciplinas propostas para o currículo básico, podemos observar a criação de um currículo que evidenciava a linha tecnicista de formação, deixando em desvantagem e desvalorizada a linha humanística, a qual abarca a vertente cultural da formação. Na opinião de Castro (2000), o currículo mínimo atendeu a algumas reivindicações das escolas e das associações de classe (na época, formadas pelos próprios professores, os quais eram os representantes dos movimentos profissionais) e trouxe também a padronização do ensino em Biblioteconomia.

Sendo assim, a partir de todos os dados históricos, foi possível observar que a realização de eventos de pesquisa abordando a Biblioteconomia e a CI, as contribuições dos docentes, dos profissionais, das associações, juntamente com o surgimento e o aumento das pesquisas, contribuíram para a visibilidade da área e para o aperfeiçoamento do profissional conforme a exigência do mercado de trabalho e da sociedade.

Cabe reforçar que o fazer do bibliotecário deve ir além de suas práticas técnicas, o profissional deve olhar para o contexto social dos sujeitos com os quais estabelece relações por meio da biblioteca ou unidade informacional em que atua. Nessa perspectiva, uma das formas de "aproximação social" com o usuário é justamente através das práticas voltadas aos contextos disseminadores e promotores da cultura, utilizando-se dos elementos concernentes à ela. Portanto, os conteúdos de formação do referido profissional também devem atender às demandas voltadas aos cenários que envolvam o usuário no contexto cultural. 


\section{CONSIDERAÇÕES FINAIS}

Esta pesquisa teve como objetivo investigar a presença de disciplinas que abordem a mediação cultural nas matrizes curriculares dos cursos de Biblioteconomia no Brasil. Sendo assim, por meio do Portal e-Mec conseguimos realizar o levantamento de todas as instituições de ensino que ministram o curso de graduação em Biblioteconomia. Por meio das informações presentes no Portal e-Mec, observamos que em algumas instituições a nomenclatura do curso não é indicado apenas como Biblioteconomia, mas também como Biblioteconomia e Documentação.

Por meio da análise das matrizes curriculares dos cursos de graduação em Biblioteconomia no Brasil, identificamos que a grande maioria das instituições ofertam os cursos de graduação no período noturno. No montante total de cursos avaliados, apenas quatro instituições oferecem turmas no turno matutino e noturno e somente na UFF o curso é ministrado em período integral, com duração de quatro anos. De um modo geral, todas as instituições consideram o período de quatro anos, divididos em oito semestres, ideal para a realização e conclusão da graduação.

Para o início das análises, separamos as disciplinas conforme as nomenclaturas são apresentadas nas matrizes curriculares. Para isso, utilizamos filtros para refinarmos as disciplinas, baseados em termos que teriam relação com o tema pesquisado: mediação cultural, cultura, mediação da informação, mediação e mediações.

Ao seguirmos os filtros de refinamento, encontramos duas disciplinas denominadas mediação cultural presentes nos currículos da USP, no Campus de Ribeirão Preto, e na Unesp, campus Marília, as quais possuem caráter optativo, e as nomenclaturas são, respectivamente, Mediação cultural: organização de acervos e produtos e Mediação cultural e da informação. A disciplina ministrada na USP possui carga horária de 60 horas e na Unesp de 30 horas.

Ao utilizarmos o filtro com o termo "Cultura", várias disciplinas foram identificadas. Porém, ao levarmos em consideração o tema pesquisado, analisando as ementas das disciplinas, constatamos que algumas delas não possuem relação com o assunto desta pesquisa. Por outro lado, também identificamos, utilizando o mesmo filtro, disciplinas com a nomenclatura de ação cultural, que, de acordo com Coelho (1999), é uma das práticas da mediação cultural e, assim, estaria relacionada com esta pesquisa.

Desta forma, identificamos na UFES, na UFC e na UDESC a presença de disciplinas denominadas como Ação cultural; em instituições como UFGRS, UFS, UFBA e UFMG, a nomenclatura é Ação cultural em bibliotecas; na Furg, intitula-se Ação cultural: teoria e prática; e na UFF, como Ação cultural em unidades de informação. Sendo assim, são nove universidades que apresentam disciplinas relacionadas ao tema pesquisa.

Além das disciplinas citadas anteriormente, observamos também em mais seis instituições a presença de disciplinas que possuem relação com o assunto. Destacam-se a de Teoria da ação cultural, ministrada em universidades como USP, Unir, UFG, de caráter obrigatório; a de Análise das práticas culturais e discursivas, na UFScar, e a de Centros culturais, bibliotecas públicas e escolares, na UEL, também obrigatórias. Na UFAL é ofertada a disciplina Biblioteca e ação cultural e a de Contação de história, a qual nos despertou interesse mesmo não seguindo os filtros utilizados, pois, segundo Cabral (1999), é uma das práticas realizadas na ação cultural.

Outros termos utilizados como filtros foram mediação e mediação da informação, os quais estão disponíveis em seis matrizes curriculares: na UFRJ, como Mediação da leitura; na UFPE, como Mediação da informação e relações etnicorraciais; na UEL, com o título Mediação da informação e do conhecimento; na UFG, denominada Serviços, produtos e mediação da informação; na UNESP, intitulada Mediação e recepção da informação; e, por fim, na UFPA como Mediação e uso da informação e Práticas de mediação da informação. 
Durante a coleta e a análise dos dados, observamos algumas limitações, uma delas referente a características deste tipo de abordagem de pesquisa documental, uma vez que pode restringir a coleta e análise do que somente está explicitado e registrado oficialmente nos sites das instituições e muitas vezes, ocorre que a documentação disponível pode não estar atualizada.

Outra limitação se deu pelo motivo de que em algumas universidades os planos de ensino das disciplinas não estavam disponíveis online. Desta forma, foi realizado contato via email e telefone. Porém, UFPE, UNIR, UFGRS, FURG, UFF, UNIRIO, UESPI, UFCA, UFRJ, mesmo após inúmeros contatos, não enviaram respostas e, por este motivo, foi impossível realizar a análise dos planos de ensino das disciplinas ofertadas nestas universidades. Esse fato também inviabilizou a análise detalhada de oito universidades.

Desta forma, ao estudarmos sobre as reformas dos currículos e os currículos atuais observamos que os debates sobre as linhas tecnicista e humanista da Biblioteconomia e a tentativa de equilíbrio entre elas estão presentes desde o surgimento da graduação no Brasil. Por meio da análise das matrizes curriculares atuais, verificamos que ainda não existe um equilíbrio entre as duas linhas da Biblioteconomia.

Esta falta de equilíbrio gerou interferências na formação do bibliotecário. Sendo assim, observamos que em algumas instituições é necessária uma revisão e atualização das matrizes curriculares, não somente sobre as questões entre as linhas de atividades, mas também atualizações em relação aos suportes e serviços que estão disponíveis para a atividade biblioteconômica.

Sendo assim, para findarmos, os resultados encontrados reforçam a necessidade dos colegiados verificarem a inclusão da mediação cultural e das ações culturais em suas matrizes curriculares, pois os estudantes devem ser preparados para atuar dentro deste aspecto social da CI. Esperamos que os resultados desta pesquisa possam contribuir para a discussão referentes as novas e possíveis reformas nas matrizes curriculares dos cursos de Biblioteconomia. Presumimos também contribuir para a ampliação das discussões referente a mediação cultural e ainda que esta pesquisa possa incutir em outros pesquisadores a abordagem de temas correlatos ao abordado na Ciência da Informação.

\section{REFERÊNCIAS}

ALMEIDA, Marco Antônio. Mediação cultural e da informação: considerações socioculturais e políticas em torno de um conceito. In: ENCONTRO NACIONAL DE PESQUISA EM CIÊNCIA DA INFORMAÇÃO, 8, 2007, Salvador. Anais... Salvador: ANCIB, 2007. Disponível em: <http://www.enancib.ppgci.ufba.br/artigos/GT3--212.pdf>. Acesso em: 26 fev. 2016.

ALMEIDA JÚNIOR, Oswaldo Francisco de. Mediação da informação e múltiplas linguagens. Tendências da Pesquisa Brasileira em Ciência da Informação, Brasília, v. 2, n. 1, p. 89103, jan. / dez. 2009. Disponível em:

<http://inseer.ibict.br/ancib/index.php/tpbci/article/view/17/39 >. Acesso em: 15 set. 2017.

BRASIL. Ministério da Educação. Conselho Nacional de Educação. Parecer CNE/CES 492/2001 de 04 de julho de 2001. Dispõe sobre as Diretrizes Curriculares Nacionais dos cursos de Filosofia, História, Geografia, Serviço Social, Comunicação Social, Ciências Sociais, Letras, Biblioteconomia, Arquivologia e Museologia. Diário Oficial [da] República Federativa do Brasil, Brasília, 9 jul. 2001. Seção 1, p. 50. 
Disponível em: $<$ http://portal.mec.gov.br/cne/arquivos/pdf/CES0492.pdf $>$. Acesso em: 23 maio 2017.

CABRAL, Ana Maria Rezende. Ação cultural: possibilidades de atuação do bibliotecário. In: VIANNA, Márcia Milton; CAMPELLO, Bernadete; MOURA, Victor Hugo Vieira.

Biblioteca escolar: espaço de ação pedagógica. Belo Horizonte: EB/UFMG, 1999. p. 39-45. Disponível em: 〈http://gebe.eci.ufmg.br/downloads/106.pdf >. Acesso em: 05 maio. 2018.

CANEDO, Daniele. “Cultural é o quê?”: reflexões sobre o conceito de cultura e a atuação dos poderes públicos. In: ENCONTRO ESTUDOS MULTIDISCIPLINARES EM CULTURA ENECULT, 5. Anais eletrônicos... Salvador: Universidade Federal da Bahia, 2009. Disponível em: $<$ http://www.cult.ufba.br/enecult2009/19353.pdf $>$. Acesso em: 26 jan. 2016.

CASTRO, César. História da biblioteconomia brasileira: perspectiva histórica. Brasília: Thesaurus, 2000.

COELHO, Teixeira. Dicionário crítico de política e ação cultural: cultura e imaginário. 2.ed. São Paulo: Iluminuras, 1999. 384 p.

DARRAS, Bernard. As várias concepções da cultura e seus efeitos sobre os processos de mediação da cultura. In: BARBOSA, Ana Mae; COUTINHO, Rejane Galvão.

Arte/Educação como mediação cultural e social. São Paulo: Unesp, 2009. 347p.

DAVALlON, Jean. A mediação: a comunicação em processo. Prisma.com. n.4, jan. 2007. Disponível em: <http://revistas.ua.pt/index.php/prismacom/article/view/645>. Acesso em: 15 set. 2017.

DARRAS, Bernard. As várias concepções da cultura e seus efeitos sobre os processos de mediação da cultura. In: BARBOSA, Ana Mae; COUTINHO, Rejane Galvão.

Arte/Educação como mediação cultural e social. São Paulo: Unesp, 2009. 347p.

LIMA, Celly de Brito. O bibliotecário como mediador cultural: concepções e desafios à sua formação. 182 f. 2016. Tese (Doutorado em Ciência da Informação) - Universidade de São Paulo, Escola de Comunicação e Artes, São Paulo, 2016.

LONDRINA. Prefeitura do Município de Londrina Estado do Paraná. Edital de concurso público n⿳172 de 2015. Anexo I. Dispõe sobre dos requisitos e atribuições dos cargos do concurso público nº172/2015. Jornal Oficial do Município de Londrina: imprensa oficial. Londrina, PR., 04 set. 2015. Disponível em

:<http://concursos.fafipa.org/concurso/concursos/arquivos/edital_abertura_pref_londrina.pdf? >. Acesso em: 23 maio 2017.

MARTIN-BARBERO, Jesus. Dos meios ás mediações: comunicação, cultura e hegemonia. 6.ed. Rio de Janeiro: UFRJ, 2009. 360 p.

OLIVEIRA, Amanda Leal de. A negociação cultural: um novo paradigma para a mediação e apropriação da cultura escrita. 2014. 249 f. Tese (Doutorado em Ciência da Informação) Escola de Comunicação e Artes, Universidade Estadual de São Paulo, São Paulo, 2014. 
PERROTTI, E.; PIERUCCINI, I. A mediação cultural como categoria autônoma. Inf. Inf., Londrina, v. 19, n. 2, p. 01-22, maio/ago., 2014. Disponível em: < http://www.uel.br/revistas/uel/index.php/informacao/article/view/19992>. Acesso em: 15 set. 2017.

QUINTELA, Pedro. Estratégias de mediação cultural: inovação e experimentação no Serviço Educativo da Casa da Música. Revista Crítica de Ciências Sociais, n. 94, p. 63-85, set., 2011. Disponível em: <http://www.ces.uc.pt/myces/UserFiles/livros/1097_rccs1531-94-estrategias-de-mediacao-cultural-inovacao-e-experimentacao-no-servico-educativoda-casa-da-musica.pdf. Acesso em: 15 set. 2017.

RASTELI, Alessandro; CALDAS, Rosangela Formentini. Cultura, Ação e Mediação nas em Bibliotecas. In: Encontro de Pesquisa em Informação e Mediação (EPIM). 2, 2015, Marília. Anais... Marília: Unesp, 2015, p3-49. Disponível em: < http://gicio.marilia.unesp.br/index.php/IIEPIM/IIEPIM/paper/viewFile/3/49 >. Acesso em: 02 fev. 2018.

SANTOS, José Luiz dos. O que é cultura. São Paulo: Brasiliense. 2006. 91 p. (Coleção Primeiros Passos; 110).

SANTOS NETO, João Arlindo dos. Mediação Implícita da Informação no discurso dos bibliotecários da Biblioteca Central da Universidade Estadual de Londrina (UEL). 193f. 2014. Dissertação (Mestrado em Ciência da Informação) - Universidade Estadual Paulista "Júlio de Mesquita Filho", Faculdade de Filosofia e Ciências, Marília, 2014.

SIGNATES, Luiz. Estudo sobre o conceito de mediação. Novos Olhares: Revista de Estudos sobre Práticas de Recepção a Produtos Midiáticos - ECA/USP, São Paulo, n. 2, jul./dez. 1998. Disponível em: $<$ http://www.revistas.univerciencia.org/index.php/novosolhares/article/viewFile/8311/769 4>. Acesso em: 15 set. 2017.

SILVEIRA, Fabrício José Nascimento da. Biblioteca como lugar de práticas culturais: uma discussão a partir dos currículos de Biblioteconomia no Brasil. 246 f. 2007. Dissertação (Mestrado em Ciência da Informação) - Universidade Federal de Minas Gerais, Belo Horizonte, 2007. 